\title{
Industry looks to buck bias in emerging 'adaptive' designs
}

Adaptive clinical trials, in which aspects such as medical endpoints and sample sizes can be modified midtrial, are catching on in the pharmaceutical industry to make drug development both faster and cheaper. But as the industry stakes out shortcuts, many researchers are concerned that they might also shortcut the integrity of clinical trials.

At a two-day conference in late April, representatives from industry and academia met in Philadelphia to discuss how adaptive decisions can be made without allowing the bias of decision-makers from compromising the trial.

The problem is one that the US Food and Drug Administration (FDA) is still coming to grips with. "We need more experience evaluating adaptive designs to improve our confidence in them," Sue-Jane Wang, associate director of adaptive designs in the FDA's Office of Biostatistics, told meeting attendees.

Potential issues with adaptive designs run the gamut from poor data safeguards to sloppy implementation of changes. For example, when interim trial data is compiled to consider an adaptive change, study sponsors might be biased toward cost-saving changes and shade the statistical analysis accordingly, rather than basing it on safety or effectiveness. On the implementation end, if an adaptive change involves, for instance, a new dosing scheme, then any changes in dose appearance could unblind study subjects and trial investigators to their treatment.

Such concerns led the FDA to release draft guidance on adaptive designs earlier this year; public comments were accepted until 1 June. In its current iteration, the guidance stresses extensive planning of potential trial changes, as well as statistical safeguards, so study decisions are neither reactionary nor biased for the sponsor. To underscore this point, Wang noted that the 50-page document mentions the word 'bias' more than 70 times.

Industry officials also remain concerned about unduly influencing the course of ongoing trials. "You can never be too careful," says Keaven Anderson, executive director of statistics for Merck Research Laboratories in North Wales, Pennsylvania.

Many in the industry, including Merck, say they are taking a highly stringent approach to adaptive designs, implementing both data- monitoring committees and independent statistical analysts who are blinded to trial features to ensure a proper firewall against sponsor bias. Wang, who herself said this format is preferable to sponsors handling all aspects, also added that it's commonly seen among the studies thus far submitted to the FDA.

The industry is "still figuring things out," says Micheline Marshall, former director of clinical pharmacy for Wyeth in Collegeville, Pennsylvania, who was also in attendance at the meeting. In addition to challenges associated with handling data, adaptive trials make it hard to ensure a seamless supply chain, as manufacturers often must adjust dosages without clinical investigators and patients noticing.

As it hones its guidance on adaptive trials, the FDA is thus putting an emphasis on extensively documenting the design and various safeguards of such trials. With more adaptive studies making it through the pipeline, it's only a matter of time before industry and regulators themselves adapt to this new trend.

Christian Torres, New York

\section{Stem cell decision could rewrite rules of patentability}

For the past decade, many researchers have complained bitterly that a trio of hotly contested patents has thwarted potentially life-saving research involving embryonic stem cells. Now, a decision to overturn one of these claims may radically change the notion of what's patentable in the life sciences.

The patents, held by the Wisconsin Alumni Research Foundation (WARF) and based on work by University of Wisconsin-Madison stem cell pioneer James Thomson, cover preparations of primate and human embryonic stem cells and methods for deriving them. In 2006, the New York-based Public Patent Foundation (PPF) led efforts to challenge the three patents on grounds that the claims were too broad and not sufficiently unique compared to similar techniques in mice.

The US Patent and Trademark Office ultimately ruled in WARF's favor, in 2008, after the foundation narrowed its claims.
Two of those decisions were final, but, because a system for appealing patents was put in place in 1999 applying to all patents from then on, and the third claim was filed in 2001, the PPF could legally appeal the third decision.

On 28 April, the US patent agency upheld the PPF's appeal. The reversal serves as a precedent should WARF attempt to defend the other two patents against new lawsuits as well, says Dan Ravicher, executive director of the PPF, which also led the successful campaign against Myriad's two breast cancer gene patents in partnership with the American Civil Liberties Union. The court's opinion "directly impacts the one patent, but there's no argument that it would not similarly invalidate the other two patents had we had the right to appeal them, as well," Ravicher says.

Greg Bonfiglio, managing partner of Proteus Venture Partners, a Palo Alto, California-based investment and advisory firm for regenerative medicine companies, says the ruling now sets a higher bar on obviousness for all biomedical patents. "The line has now been drawn much more broadly," he says. "One way to read this opinion is, 'anything that was done in mouse is now not patentable in humans."

If the patent office adopts that view, the WARF decision could potentially affect the intellectual property landscape for induced pluripotent stem (iPS) cells. "The cases going forward, whether they're embryonic stem cells or iPS cells, are going to be narrow," says David Resnick, a patent attorney with Nixon Peabody in Boston.

So far, the Patent and Trademark Office has awarded only one iPS-related patent, granted to San Diego stem cell company Fate Therapeutics, and the patent is fairly limited in scope (Nat. Med. 16, 246, 2010).

Alla Katsnelson, New York 